\title{
Hydrodynamics modelling utilizing the EFDC Explorer model for the sustainable management of Canal del Dique-Guajaro hydrosystem, Colombia
}

\author{
F. Torres-Bejarano ${ }^{1}$, J. Padilla $^{1}$, C. Rodríguez-Cuevas ${ }^{2}$ \\ \& R. Cantero ${ }^{1}$ \\ ${ }^{I}$ Faculty of Environmental Sciences, Coast University, Colombia \\ ${ }^{2}$ Faculty of Engineering, University of San Luis Potosi, Mexico
}

\begin{abstract}
Guájaro reservoir is located in the south east of Atlántico department (Colombia). This water body is the most important in the region since its construction in 1964. It is supplied by an artificial channel (Canal del Dique) by means of a two floodgate system. As a result of excess nutrients and other pollution loads from the drainage basin in recent decades, Guájaro reservoir has suffered eutrophication and other pollution problems, however it still continues to be exploited. For this reason, it is necessary to regulate the hydraulic structures that supply this water body, as they play an important role in managing levels and these in turn for the purpose of water supply and environmental purposes. The present work has been carried out as a sustainability management alternative of the reservoir. The implementation of a two-dimensional hydrodynamic model (EFDC Explorer) and its calibration is implemented using a time series of the free surface levels, and comparing the measured velocities and those estimated by the model for two different climatic periods, to assist the operation of Hydrosystem Canal del DiqueGuajaro. The corresponding comparisons showed a good behaviour between measured and simulated data. Based on the quantitative results of the NashSutcliffe reliability method, it is considered that the results are quite satisfactory to estimate and predict the amount of water flowing in and out of the reservoir through the hydrosystem channel reservoir.
\end{abstract}

Keywords: hydrodynamics modelling, water resource management, water management, EFDC Explorer. 


\section{Introduction}

Currently, there is widespread concern in relation to global environmental degradation. Phenomena such as global warming, caused mainly by industrial development and unsustainable population growth, makes it vital to have tools that help us to understand these phenomena and evaluate scenarios in case of emergency events, in order to take effectively accurate decisions, attached to reality [1].

When solving problems related to water resources both a spatial representation of the system and the understanding of such problems are needed. In this regard, the hydrodynamic models can represent the characteristics and behaviour of system relations, supported on the associated predictive analytics capabilities, which are most useful in solving planning and management of complex problems in aquatic resources. The Integrated Water Resources Management (IWRM) nowadays is a prerequisite for environmental preservation and economic development. However, the implementation of proposed actions incorporates significant hampered due to lack of necessary data, and the lack of interactions between hydrological and ecological components [2]. According to [3], a variety of software and modelling technologies are emerging in the form of "support tools" to better handle the problems of use of scientific knowledge in environmental research and planning activities. These technologies are motivated by legitimate concerns about the inefficiency of conventional research methods and to ensure that science can be effective and easy to transfer to management applications, in particular the management of water resources.

Therefore, the objective of this work is to implement a hydrodynamic numerical model to contribute to the sustainable management of water resources in the Guájaro reservoir, Colombia, considering primarily the management of water levels.

For that reason, the model Environmental Fluid Dynamics Code (EFDC) was selected because its friendliness to the pre-processing of data and its processing capacity, high performance computing and numerical robustness, plus it has been applied and successfully implemented in several study cases worldwide. In the last two decades, it has become one of the most used and technically defensible hydrodynamic models in the world. It has been applied in more than 100 water bodies and for environmental water resource management [4-9].

\subsection{Study zone description}

The Guájaro reservoir, is considered a strategic ecoregion, located at north of Colombia (Figure 1) at $10^{\circ} 42^{\prime} \mathrm{N}$ and $75^{\circ} 6^{\prime} \mathrm{W}$, a few kilometers from the Caribbean Sea. This water body covers an area of 16,000 ha, a volume of $400 \mathrm{Mm}^{3}$, drains 12,000 ha by an irrigation district, has two sets of floodgates that communicate with the Canal del Dique channel, allowing the reservoir control levels [10]. Today the floodgates have an operation protocol, to establish the actions required according to the hydrological season presented. 


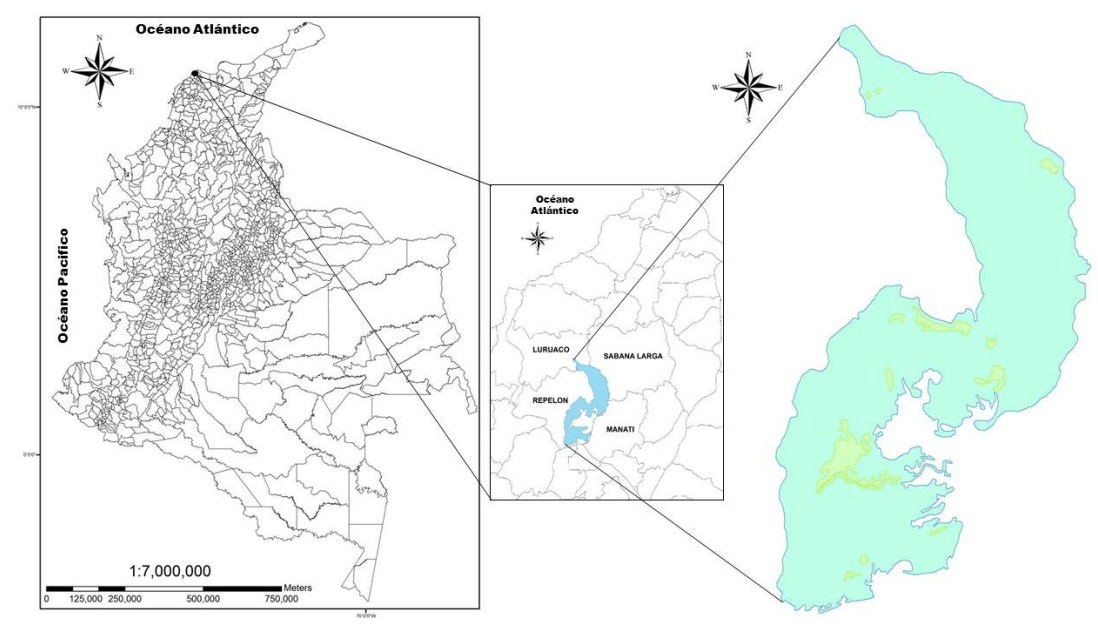

Figure 1: Study zone.

\section{Model description}

The EFDC Model was originally developed at the Virginia Institute of Marine Science and later sponsored by the US Environmental Protection Agency (US EPA). The EFDC model is a fully dynamic 2D and 3D tool, adaptable to the necessary characteristics of water bodies studies [11]. It is a hydrodynamic and water quality model that can be applied to any surface water body, including lakes and rivers. The characteristics of physical, chemical and ecological processes can be simulated by numerical functions. The EFDC was developed with a structure characterized by: a) a model built with cells of finite elements, b) with the possibility of wetting and drying in the contour processing, c) allows exchange of heat with the atmosphere, d) and simulate water quality [12]. It is a package of multi-dimensional hydrodynamic modelling, capable of simulating a diverse range of environmental and transport problems. The model solves the tridimensional momentum, free surface, hydrostatic pressure, and turbulence with varying density equations.

The EFDC Explorer 7.1 version (commercial distribution), is a comprehensive and flexible tool designed for the EFDC modelling system, which was optimized by the company Dynamic Solutions-International (DSI), who developed a user interface that makes friendly the implementation of the model, from the preprocessing of data to the post-processing of results.

\subsection{Model description}

The model develops the momentum equations (1) and (2), the continuity equation (3), the state equation (4) and the transport equations for salinity and temperature (5) and (6), all vertical integrated resolved. The model uses the sigma 
coordinate on the vertical and Cartesian or curvilinear orthogonal coordinates in the horizontal:

\section{Momentum equations}

$$
\begin{aligned}
& \overbrace{\frac{\partial(m H u)}{\partial t}}^{1}+\overbrace{\frac{\partial\left(m_{y} H u u\right)}{\partial x}+\frac{\partial\left(m_{x} H v u\right)}{\partial y}+\frac{\partial(m w u)}{\partial z}}^{2}-\overbrace{\left(m f+v \frac{\partial m_{y}}{\partial x}-u \frac{\partial m_{x}}{\partial y}\right) H v}^{3}= \\
& \overbrace{-m_{y} H \frac{\partial(g \zeta+\rho)}{\partial x}}^{4}-\overbrace{m_{y}\left(\frac{\partial h}{\partial x}-z \frac{\partial H}{\partial x}\right) \frac{\partial p}{\partial z}+\frac{\partial}{\partial z}\left(m \frac{1}{H} A_{V} \frac{\partial u}{\partial z}\right)}^{5}+Q_{u} \\
& \overbrace{\frac{\partial(m H v)}{\partial t}}^{1}+\overbrace{\frac{\partial\left(m_{y} H u v\right)}{\partial x}+\frac{\partial\left(m_{x} H v v\right)}{\partial y}+\frac{\partial(m w v)}{\partial z}}^{2}+\overbrace{\left(m f+v \frac{\partial m_{y}}{\partial x}-u \frac{\partial m_{x}}{\partial y}\right) H u}^{3}= \\
& \overbrace{-m_{x} H \frac{\partial(g \zeta+\rho)}{\partial y}}^{4}-\overbrace{m_{x}\left(\frac{\partial h}{\partial y}-z \frac{\partial H}{\partial y}\right) \frac{\partial p}{\partial z}+\frac{\partial}{\partial z}\left(m \frac{1}{H} A_{V} \frac{\partial v}{\partial z}\right)}^{5}+Q_{v}
\end{aligned}
$$

In Equations (1) and (2), the term 1 represents the rate of change of velocity with respect of time, the term 2 are the advective components and represent the movement of fluid due to inertial forces, term 3 is the Coriolis acceleration and bottom shear stresses, term 4 is the pressing force, represented by the variation of the free surface, and the term 5 the viscous stresses that cause turbulence within the flow.

\section{Continuity equation}

$$
\frac{\partial(m \zeta)}{\partial t}+\frac{\partial\left(m_{y} H u\right)}{\partial x}+\frac{\partial\left(m_{x} H v\right)}{\partial y}+\frac{\partial(m w)}{\partial z}=0
$$

\section{State equation}

$$
\rho=\rho(p, S, T)
$$

\section{Transport equation for salinity and temperature}

$$
\begin{aligned}
& \frac{\partial(m H S)}{\partial t}+\frac{\partial\left(m_{y} H u S\right)}{\partial x}+\frac{\partial\left(m_{x} H v S\right)}{\partial y}+\frac{\partial(m w S)}{\partial z}=\frac{\partial}{\partial z}\left(m \frac{1}{H} A_{b} \frac{\partial S}{\partial z}\right)+Q_{S} \\
& \frac{\partial(m H T)}{\partial t}+\frac{\partial\left(m_{y} H u T\right)}{\partial x}+\frac{\partial\left(m_{x} H v T\right)}{\partial y}+\frac{\partial(m w T)}{\partial z}=\frac{\partial}{\partial z}\left(m \frac{1}{H} A_{b} \frac{\partial T}{\partial z}\right)+Q_{T}
\end{aligned}
$$

Where $u$ and $v$ terms are the velocity components at the horizontal curvilinearorthogonal coordinates ( $x$ and $y), m_{x}$ and $m_{y}$ are the square roots of the diagonal components; $H=h+\zeta$ is the total depth, or the sum of depth and the free surface; $p$ is the physical pressure in excess of the reference density; $f$ is the Coriolis parameter, $A_{v}$ and $A_{b}$, are the terms of the vertical turbulent diffusion and vertical diffusion or Eddy viscosity; $Q_{u}$ and $Q_{v}$, representing the additional forces or sources and sinks including: turbulent diffusion and horizontal pulse, resistance vegetation Reynolds stress wave; $\rho$ represents the density; $T$ and $S$, temperature 
and salinity, respectively, $Q_{S}$ and $Q_{T}$, include the dissemination of horizontal scale of sub-mesh, and thermal sources and sinks, respectively.

Figure 2 shows the structure that uses the EFDC model for hydrodynamic surface water.

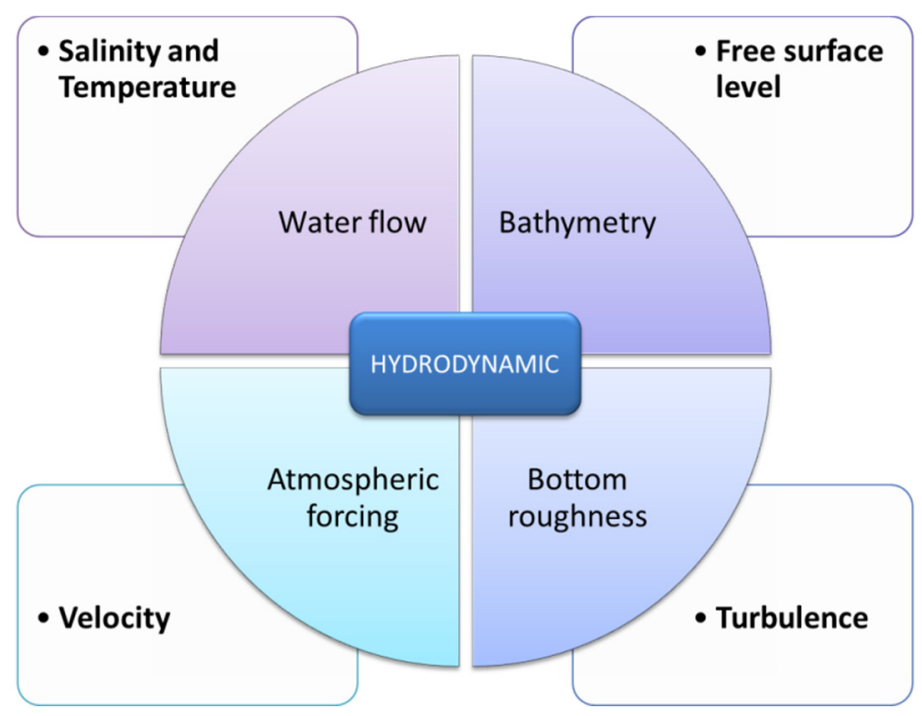

Figure 2: $\quad$ Structure of the EFDC hydrodynamic model.

\section{Methodology}

In this work a methodology that includes the implementation of the numerical model EFDC Explorer 7.1, for simulations of hydrodynamic variables in the Guájaro reservoir, also the model calibration using a statistical method to evaluate the model predictive capacity [13], and an indicator of goodness-of-fit as the NashSutcliffe efficiency coefficient [14].

Within the procedures carried out are: measurements of reservoir hydrodynamic and to do this an Acoustic Doppler Current Profiler (ADCP) was used, with a frequency range of $600 \mathrm{kHz}$ which continuously recorded the magnitude and direction of water velocities. The depths were determined with a bathymetric Sounder Garmin GPSMAP 441S. For hydrometeorology, data from monitoring stations from the Institute of Hydrology, Meteorology and Environmental Studies of Colombia (IDEAM by Spanish) were used.

\subsection{Calibration}

The purpose of the model calibration is to reproduce the mass water movement for known conditions by varying the physical parameters within rationally suitable values [15]. To calibrate the model, a total time of 15 days were simulated for two scenarios. The elevations altitudes and the corresponding area to the maximum 
level for that period were used; also outflows and inflows for dry and rain season, respectively, were determined. To verify the goodness of fit, the root mean square error (RMSE) and the Nash-Sutcliffe efficiency coefficient (Ceff) were used. The error in the model predictions is quantified in terms of units of the calculated variable by RMSE which is expressed in equation (7), followed efficiency coefficient using equation (8).

$$
\begin{aligned}
R M S E & =\sqrt{\frac{\sum_{i=1}^{n}\left(o_{i}-p_{i}\right)^{2}}{N}} \\
C e f f & =\frac{\sum_{i=1}^{n}\left(o_{i}-p_{i}\right)^{2}}{\sum_{i=1}^{n}\left(O_{i}-\bar{o}_{i}\right)^{2}}
\end{aligned}
$$

where $O_{i}$ and $p_{i}$ are the reservoir levels; $N$ is the simple number in the time series; and $\bar{O}_{i}$ is value of the time average reservoir levels.

Validation involves assessing the predictive ability of the model. This means checking the model results with observed data and adjusting the parameters until the results are within acceptable limits of accuracy.

\subsection{Data requirement}

To the model configuration and implementation, a dataset is required to specify the boundary conditions or model input and thus be able to perform the corresponding simulations in order to validate the model for the study area. All data obtained by sampling or measurement equipment, were processed and digitized in shape files and displayed in thematic maps, according to the projection WGS (Word Geodetic System) 1984 18N. The ADCP measures were processed, filtered and extracting the required values and their averaged in the water column. It is important to know that, it was necessary to obtain digitized contours of the reservoir for the corresponding dates, for this, satellite images of the sampling dates were used, obtained from the US Geological Survey, http://glovis.usgs.gov/.

\subsubsection{Bathymetry and levels}

Depth information was obtained from measurement campaigns carried out on July $18^{\text {th }}, 19^{\text {th }}$ and $20^{\text {th }}$ of 2013 for dry season and October $27^{\text {th }}, 28^{\text {th }}$ and $29^{\text {th }}$ for the rain season of the same year. Figure 3 shows graphically the range of depths of the reservoir in the two selected periods, covering the bathymetry an area of approximately $12,500 \mathrm{Ha}$.

The corresponding reservoir levels were extracted from the daily measurements records that are implemented by the environmental authority at the region, The Autonomous Corporation of Atlantic Department (CRA). These data were compared with the time series calculated by the numerical model, as shown below in Figure 7 and Figure 9.

\subsubsection{Winds}

The free surface wind effects were also considered, whose magnitudes and directions were obtained from an IDEAM meteorological station, located in the study area (Figure 4). 


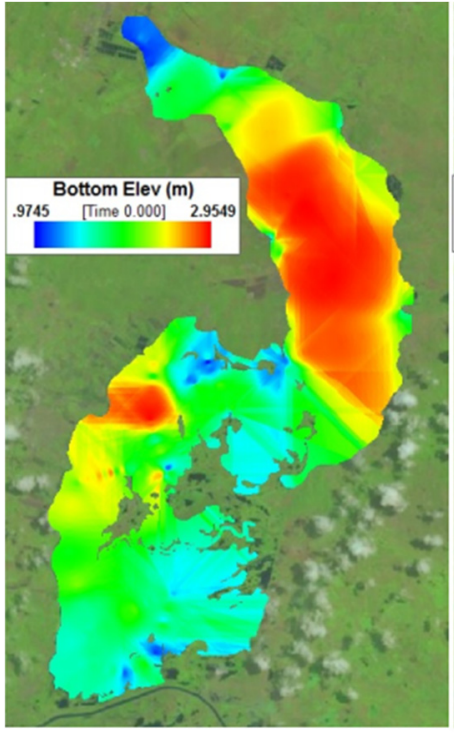

(a)

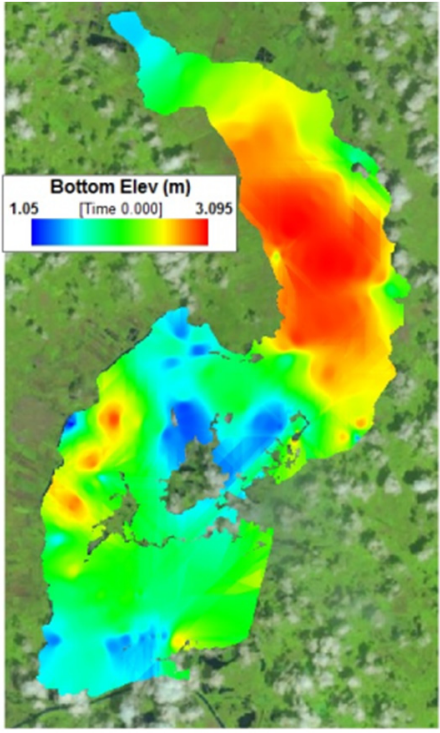

(b)

Figure 3: $\quad$ Bathymetry of Guájaro reservoir: dry season (a); rain season (b).

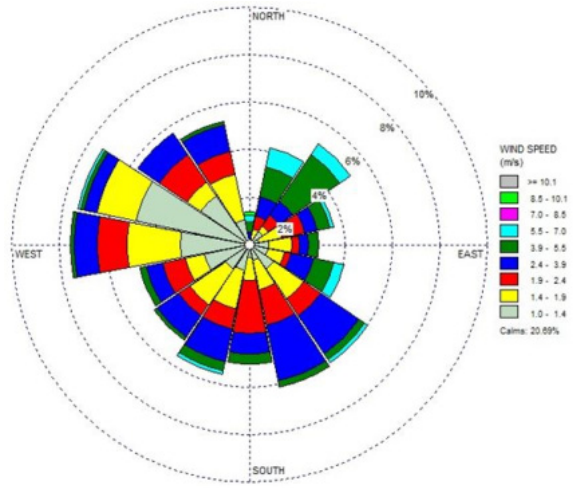

(a)

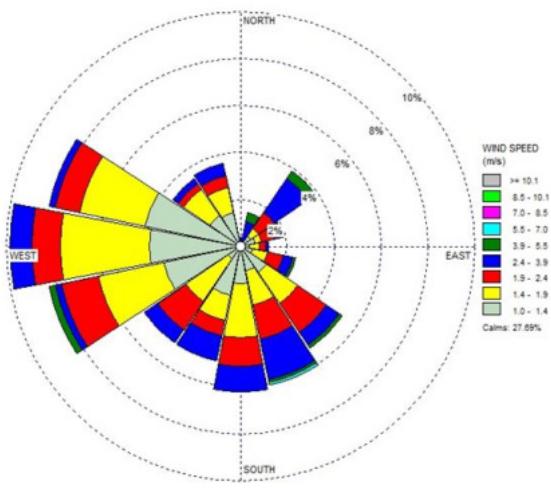

(b)

Figure 4: $\quad$ Wind rose; dry season (a), rain season (b).

\subsection{Floodgates operation and model calibration}

The Guájaro reservoir needs to be operated by hydraulic floodgates to ensure water supply; the offer cannot be guaranteed only by the supply provided by its watershed. The Canal del Dique and Guajaro connection is achieved through two floodgates systems, known as the floodgate of Limón and floodgate of Villa Rosa (Figure 5). 


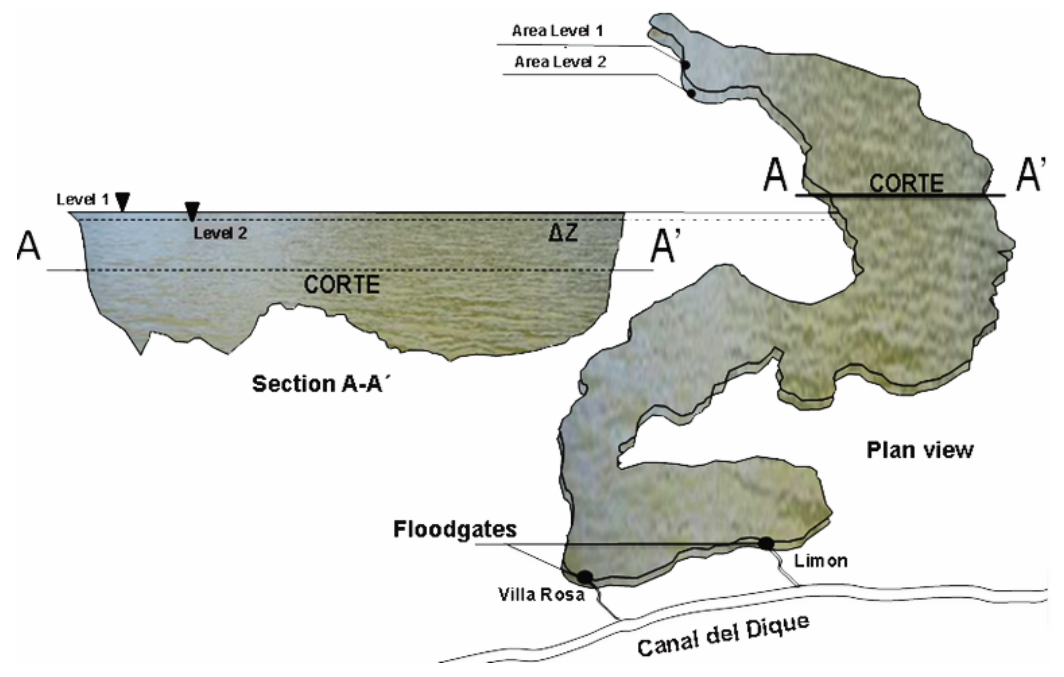

Figure 5: Identification of floodgates.

\section{Results and discussion}

\subsection{Computational grid configuration}

A mesh with $\Delta \mathrm{X}=\Delta \mathrm{Y}=30 \mathrm{~m}$ was used, for the dry season 320 elements in the horizontal direction and 600 in the vertical direction, for a total of 201,736 elements, of which 84,589 are active cells; and for rain season 334 elements in the horizontal and 600 direction in the vertical direction, for a total of 201,736 elements with 84,594 active cells (Figure 6). The time step used in each simulation was $2 \mathrm{~s}$, generating results every 2 hours.

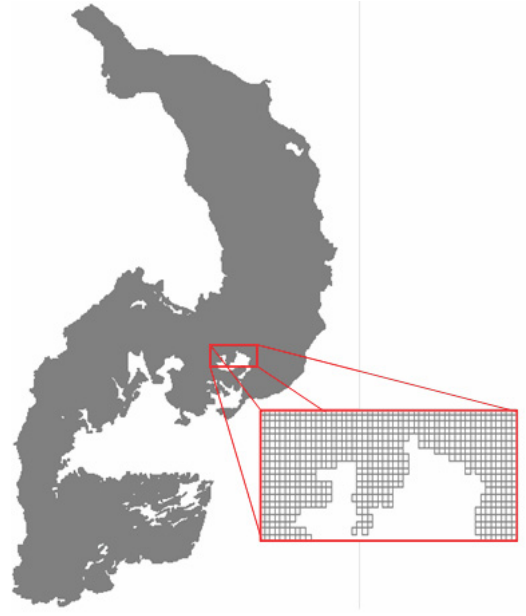

(a)

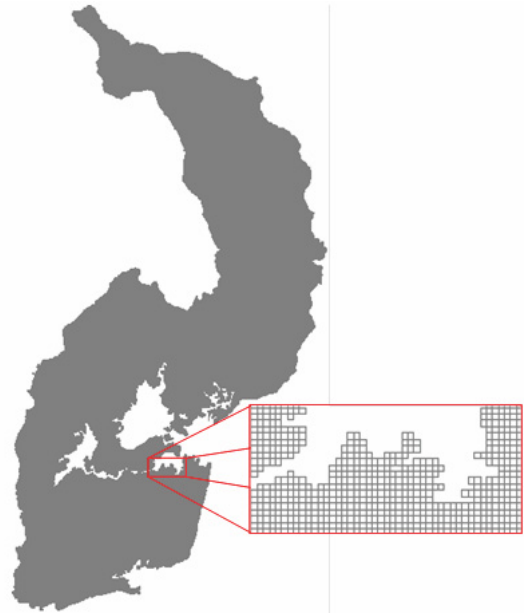

(b)

Figure 6: $\quad$ Computational grid for dry season (a) and rain season (b). 


\subsection{Dry season simulation}

The climatological measurements reported for this period show that the Guájaro reservoir reached a maximum level of 4.03 meters and, according to the water balance a minimum level of 3.91 meters. The variation of reservoir levels is shown in Figure 7. Likewise, the behavior of reservoir levels obtained with the applied numerical model is illustrated.

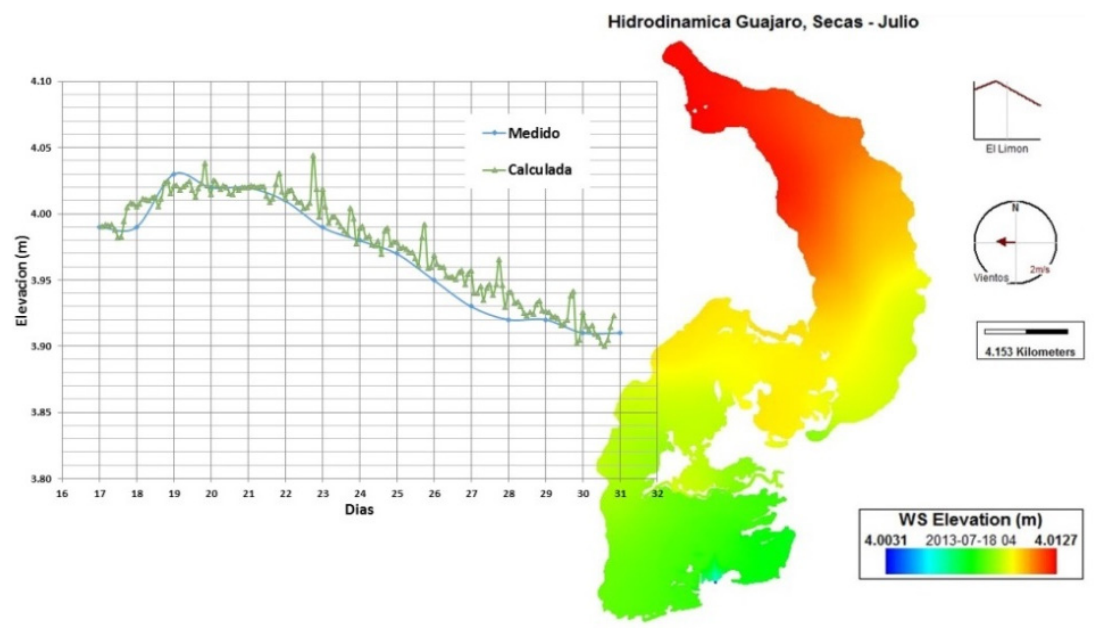

Figure 7: Behavior of measured and simulated reservoir levels for dry season.

Regarding the water body hydrodynamics, the depth averaged velocities were compared with those obtained by the numerical model. This comparison of measured and calculated velocity vectors are shown in Figure 8.

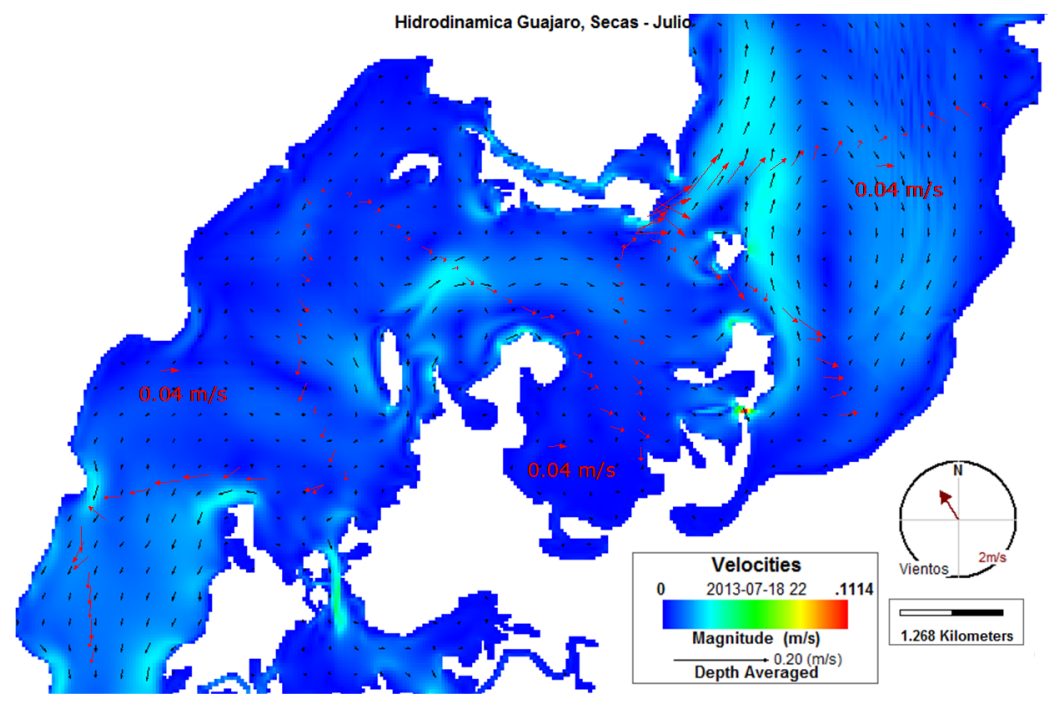

Figure 8: $\quad$ Measured (red) and simulated (black) velocities for dry season. 


\subsection{Rain season simulation}

Measured free surface level corresponding to the simulated period, show that the Guajaro reservoir had 4.08 meters over the sea level, and according to the floodgates operations the reservoir reached a maximum level of 4.16 meter over the sea. Likewise, the numerical calculated level behavior is illustrated in Figure 9.

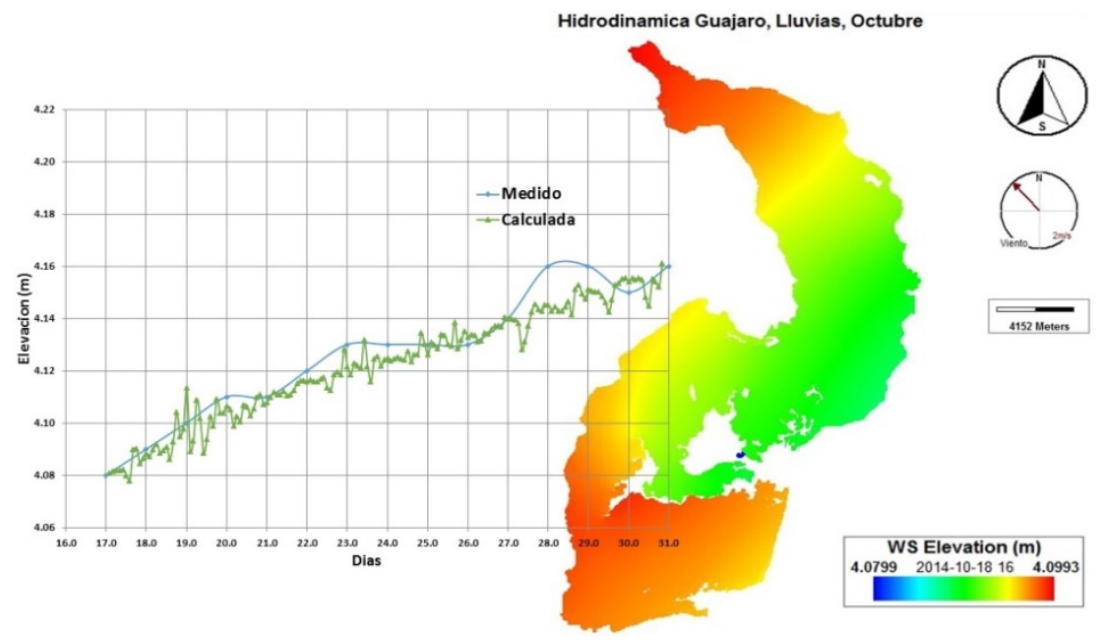

Figure 9: Behavior of measured and simulated reservoir levels for rain season.

Measured and calculated velocity vectors for rain season are shown in Figure 10. To this period, also a good correspondence between measured and calculated is found.

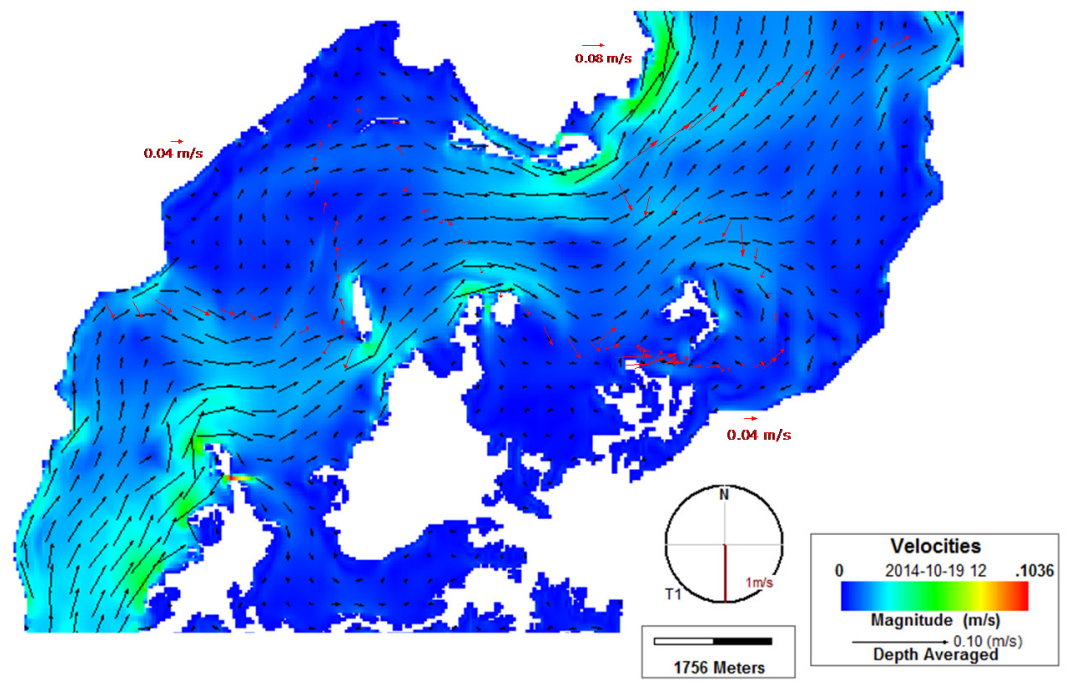

Figure 10: Measured (red) and simulated (black) velocities for rain season. 


\subsection{Calibration results}

In this work, the EFDC Explorer model results were evaluated using the RMSE and Ceff statistical method, to prove if predicted (simulated) water levels results were consistent with the observed values; for dry season $R M S E=0.016$ and Ceff $=0.87263$, for rain season $R M S E=0.018$ and $C e f f=0.92709$. This show an excellent adjustment and correlation between simulated and field observed, which means, the model results are consistent with the measurements.

\section{Conclusions}

This work shows the EFDC Explorer model calibration and validation process for the Guajaro reservoir. This process was carried out comparing the measurements for the two seasons with the calculated or simulated values. The goodness of fit estimators (Ceff) and the error RMSE, allow estimate of an appropriate way the model capacity to reproduce the data.

The models has been applied to the flow exchange study through the hydraulic structures (floodgates) that control the water levels of this reservoir, where the operation and behaviour allows the water inflow and outflow in an exchange within the hydrosystem Canal del Dique-Guajaro. In the dry season the minimum water levels are presented, forcing to take actions to counteract the water volume deficit; while for rainy season, water levels lowly highs are presented, likewise forcing to take actions to control of the excess of volume and levels of water. Attending these conditions, the selected model was calibrated and validated for both seasons, proving its ability to simulate and represent the hydrodynamic behaviour for this to climatic period.

Given the obtained results in the hydrodynamic calibration and validation process, this model is able to be implemented to estimate the water levels that can be presented in a water body, considering the climatic factor of occurrence. Besides, the importance and utility of hydrodynamic numerical modelling is demonstrated to contribute in the integrated water management and decision making.

\section{References}

[1] Torres-Bejarano, F., Ramirez, H., Denzer, R., Frysinger, S., Hell, T., \& Schlobinski, S. Linking Numerical Water Quality Models in an Environmental Information System for Integrated Environmental Assessments, Journal of Environmental Protection, 4, 126-137. 2013.

[2] Dimitriou, E. \& Zacharias, I. Quantifying the rainfall-water level fluctuation process in a geologically complex Lake catchment, Environmental Monitoring and Assessment 119(1-3), 491-506. 2006.

[3] McIntosh, B. S., Seaton, R. A. F., Jeffrey, P. Tools to think with? Towards understanding the use of computer-based support tools in policy relevant research. Environmental Modelling \& Software, Vol. 22, 640-648. doi:10.1016/j.envsoft.2005.12.015. 2007. 
[4] Kuo, A.Y., Shen, J. \& Hamrick, J.M. The Effect of Acceleration on Bottom Shear Stress in Tidal Estuaries. ASCE Journal of Waterways, Ports, Coastal and Ocean Engineering, 122, 75-83. 1996.

[5] Kim, S.C., Wright, D.L., Maa, J.P.Y. \& Shen, J. Morphodynamic Responses to Extratropical Meteorological Forcing on the Inner Shelf of the Middle Atlantic Bight: Wind Wave, Currents, and Suspended Sediment Transport. In: Spaulding, M.L., Blumberg, A.F. (Eds.), Estuarine and Coastal Modeling V. ASCE, New York, pp. 456-466. 1998.

[6] Moustafa, M.Z., Hamrick, J.M. Calibration of the Wetland Hydrodynamic Model to the Everglades Nutrient Removal Project. Water Quality and Ecosystem Modeling, 1, 141-167. 2000.

[7] Ji, Z.G., Morton, M.R. \& Hamrick, J.M. Wetting and Drying Simulation of Estuarine Rocesses. Estuarine, Coastal and Shelf Science, 53, 683-700. 2001.

[8] Park, K., Jung, H.S. Kim, H.S., Ahn, S.M. Three-Dimensional Hydrodynamic Eutrophication Model (HEM-3D): Application to KwangYang Bay, Korea. Marine Environmental Research, 60, 171-193. 2005.

[9] Luo, F., Li, R.J. 3D Water Environment Simulation for North Jiangsu offshore sea based on EFDC. Journal of Water Resource and Protection, 1, 41-47. 2009.

[10] Uninorte (Universidad del Norte), Guajaro reservoir: Hydraulic and environmental assessment of current conditions. pp. 3-4. 2009.

[11] Hamrick, J.M. A Three-dimensional environmental fluid dynamic computer code: theoretical and computational aspects, The College of William and Mary, Virginia institute of marine science, p. 317, Special report. 1992.

[12] Wang, Y., Jiang, Y., Liao, P., Gao, X., Huang, H., Wang, X. Song, X. Lei, 3-D hydro-environmental simulation of Miyun reservoir, Beijing. Journal of Hydro-environment Research, English (in Press), 1-13. 2013.

[13] Molnar, P. Calibration. Watershed Modelling. Institute of Environmental Engineering, Chair of Hydrology and Water Resources Management, ETH Zürich. Switzerland, 2011.

[14] Nash, J.E., Sutcliffe, J.V. River flow forecasting through conceptual models, part I: A discussion of principles. J. Hydrol. Hydrology, 10, 282 290. 1970.

[15] Palacio, C., García, F., García, U. Calibración de un Modelo Hidrodinámico 2D para la Bahía de Cartagena. DYNA, 164 (77), 152-166. 2010. 